\title{
Pseudohyponatremia Leading to a Fatal Outcome in a Patient With Familial Hypertriglyceridemia
}

\author{
Amanda Dawson ${ }^{1}$, Anish Kanukuntla ${ }^{1}$, Priyaranjan Kata ${ }^{1}$, Rana Ali ${ }^{2}$, Pramil Cheriyath ${ }^{1}$ \\ 1. Internal Medicine, Hackensack Meridian Ocean Medical Center, Brick, USA 2. Internal Medicine, Hackensack \\ Meridian Health Jersey Shore University Medical Center, Neptune City, USA
}

Corresponding author: Priyaranjan Kata, priyaranjankata@outlook.com

\begin{abstract}
Serum sodium assay is a commonly performed laboratory test in a clinical setting and the results are taken for granted without being aware of the actual methods involved. In conditions like hyperlipidemia and hyperproteinemia, excessive lipids in serum dilute the water component of the serum. Since sodium is dissolved only in the aqueous phase of serum, the sodium content per unit volume of plasma is reduced. Currently, most of the laboratories use the indirect ion-selective electrode method (ISE), where the plasma sample is diluted before the measurement. Indirect ISE may not give accurate results in conditions with higher serum lipid and protein levels. Overcorrection of the serum sodium levels in pseudohyponatremia may cause serious complications. We report a case of a 26-year-old Asian male with a past medical history of chronic pancreatitis, familial hypertriglyceridemia, and fatty liver who presented to the emergency department with acute pancreatitis. Initially, the patient was found to have hyponatremia and he was started on hypertonic saline for one day. Later the patient's condition deteriorated and then it was determined that serum sodium results were a measurement artifact since the patient had extremely high levels of triglycerides. After realizing that it was a measurement artifact, the saline infusion was stopped and he was started on desmopressin. However, the patient deteriorated neurologically and expired later. As this patient had normal sodium levels, administration of hypertonic saline led to a fatal outcome.
\end{abstract}

Categories: Internal Medicine, Neurology

Keywords: hyperlipidemia, hypertriglyceridemia, pseudohyponatremia, global cerebral edema, hyperproteinemia

\section{Introduction}

Serum sodium assay is one of the most commonly performed laboratory tests in a hospital setting. Most often, the results are taken for granted without being aware of the actual methods involved in the lab procedures. However, in certain conditions, the reported lab results may not reflect the actual values, resulting in mismanagement of patients.

Review began 07/26/2021 Review ended 08/04/2021 Published 08/10/2021

\section{○ Copyright 2021}

Dawson et al. This is an open access article distributed under the terms of the Creative Commons Attribution License CC-BY 4.0., which permits unrestricted use, distribution, and reproduction in any medium, provided the original author and source are credited.
Hyponatremia is defined as the plasma sodium level less than $135 \mathrm{mmol} / \mathrm{L}$ and its prevalence in a hospital setting is up to $12 \%$ [1-3]. Pseudohyponatremia refers to low serum sodium in the presence of normal plasma tonicity [4-6]. In pseudohyponatremia, the water component is diluted by non-aqueous materials such as lipids and proteins. In conditions like hyperlipidemia and hyperproteinemia, abnormally high levels of these large molecules replace the aqueous phase of plasma, thus resulting in a reduced amount of serum electrolytes per unit volume of serum $[6,7]$. When measured with conventional flame photometry or indirect potentiometry, which involves prior dilution of the samples, the measured sodium concentration is low but the true plasma concentration is normal [7]. Not being aware of this artifact and correction of sodium in these conditions result in increased morbidity and mortality [8]. Since these concepts are not usually recognized in regular clinical practice, it would be helpful to review the methodology involved along with the events that led to a fatal outcome in this patient.

\section{Case Presentation}

A 26-year-old Asian male with a past medical history of chronic pancreatitis, familial hypertriglyceridemia, and fatty liver presented to the emergency department complaining of nausea and abdominal pain for one day that had gotten progressively worse. The pain was sharp in quality. At the time of presentation, his vital signs showed a temperature of $97^{\circ} \mathrm{F}$, a pulse of 107 beats per minute, a respiratory rate of 20 breaths per minute, and blood pressure of $188 / 99 \mathrm{~mm}$ Hg. Physical examination revealed extensive xanthomas located throughout his body. The abdomen was soft, mildly tender to palpation in the right upper quadrant, and bowel sounds were present. Further work up in the emergency room showed a WBC count of 12,000/mL (4.5$\left.11.0 \times 10^{3} / \mu \mathrm{L}\right)$, sodium $112 \mathrm{mEq} / \mathrm{L}(135-145 \mathrm{mEq} / \mathrm{L})$, blood glucose $283 \mathrm{mg} / \mathrm{dL}(70-99 \mathrm{mg} / \mathrm{dL})$, bicarbonate 18 $\mathrm{mEq} / \mathrm{L}(23-30 \mathrm{mEq} / \mathrm{L})$, anion gap $5 \mathrm{mEq} / \mathrm{L}$ (10-16 mEq/L), amylase $844 \mathrm{U} / \mathrm{L}$ (30-110 U/L), lipase $2170 \mathrm{U} / \mathrm{L}$ (10$140 \mathrm{U} / \mathrm{L}$ ), and serum osmolality $331 \mathrm{mOsm} / \mathrm{kg}$ (275 to $295 \mathrm{mOsm} / \mathrm{kg}$ ). The lipid profile showed elevated triglyceride levels of $5805 \mathrm{mg} / \mathrm{dL}$ (less than $150 \mathrm{mg} / \mathrm{dL}$ ). CT scan of the abdomen and pelvis showed severe acute pancreatitis with diffuse pancreatic enlargement with inflammatory changes and free fluid (Figure 1). 


\section{Cureus}

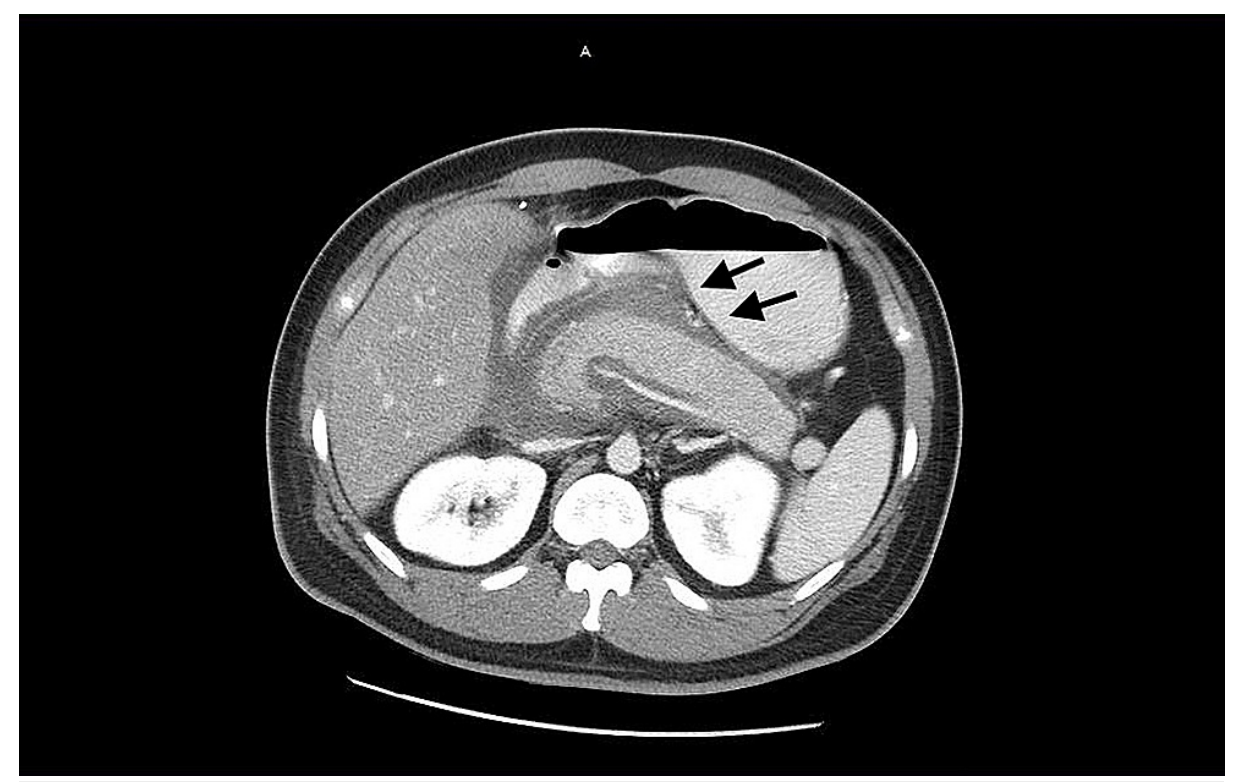

\section{FIGURE 1: CT abdomen}

Imaging findings suggestive of severe acute pancreatitis with diffuse pancreatic enlargement, adjacent inflammatory changes, and free fluid.

Later on that day, he was transferred to the ICU and requested to be seen by pulmonary critical care and nephrology. The patient was started on IV fluids. Because the patient's repeated lab values consistently revealed critically low sodium levels ( $109 \mathrm{meq} / \mathrm{L})$, he was started on $3 \%$ saline at a rate of $25 \mathrm{ml} /$ hour for the next eight hours with frequent electrolyte monitoring. Overnight, the patient was on hydromorphone for pain control. The following morning, the patient went into cardiac arrest; spontaneous circulation was restored in ten minutes. He was intubated and placed on ventilator support. His immediate arterial blood gas showed a $\mathrm{PH}$ of $7.09, \mathrm{PCO}_{2}$ of 36.2, $\mathrm{PO}_{2}$ of 143.1 , and a bicarbonate level of $10 \mathrm{meq} / \mathrm{L}$. Later, it was realized that the patient had pseudohyponatremia due to his underlying hypertriglyceridemia. He was started on an IV bicarbonate drip and given one dose of desmopressin. Despite the ongoing treatment, the patient became unarousable and unresponsive to painful stimuli. On neurological examination, his eyes had an upward deviation with a sluggish pupillary response to light. An immediate metabolic panel was repeated which then showed a sodium level of $134 \mathrm{meq} / \mathrm{L}$. A new CT of the head showed global cerebral edema (Figure 2). Because of the patient's poor prognosis, he was referred for comfort care after discussing with his family. Later that day, the patient passed away. 


\section{Cureus}

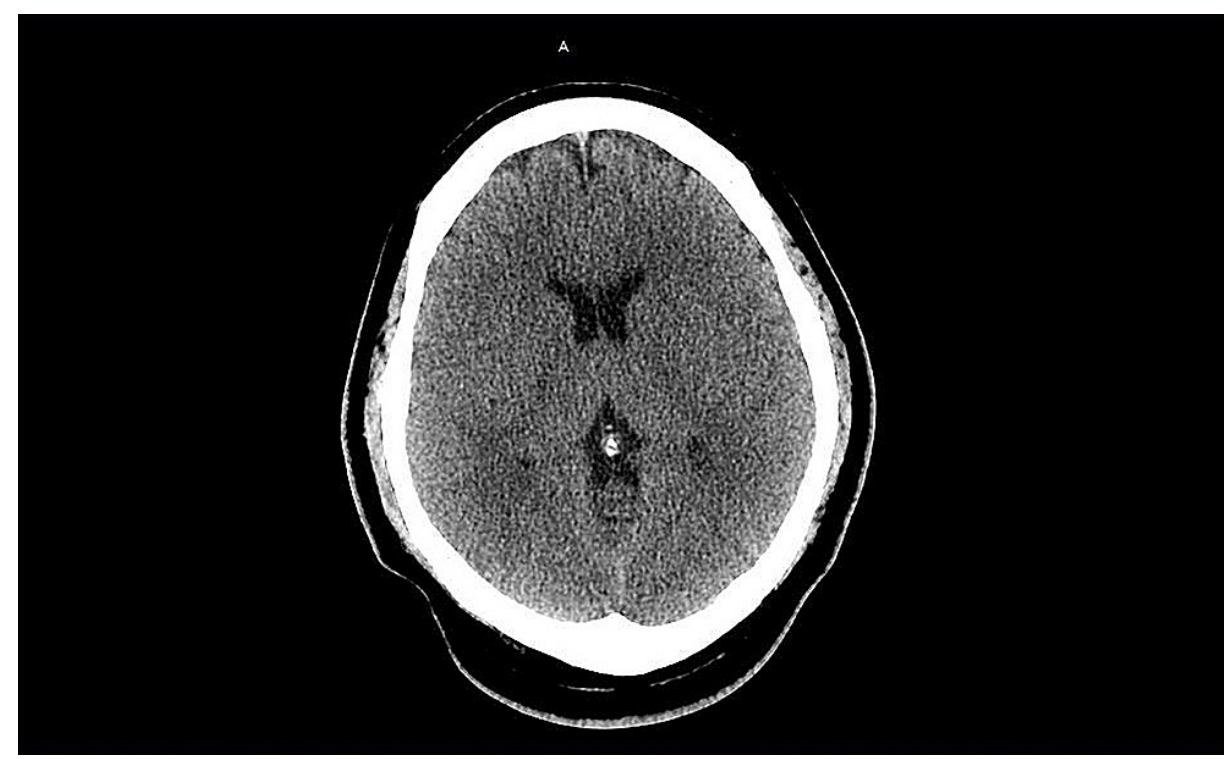

FIGURE 2: CT head

Imaging findings suggestive of early global cerebral edema.

\section{Discussion}

Human serum is composed of $93 \%$ water and $7 \%$ non-aqueous components (lipids, proteins, etc.) by volume [9]. All serum electrolytes including sodium are dissolved in the aqueous component. Increased serum lipid and protein components in blood result in a relative decrease in the water content of plasma but the proportions of serum electrolytes in the aqueous component remain unchanged. Serum sodium concentration is normally measured in milliequivalents per liter. In conditions like hyperlipidemia and hyperproteinemia, there is a relative decrease in plasma water content as it is replaced by serum lipids or proteins. In such cases, the measurement of serum sodium concentration is significantly reduced in the water component.

The measurement of sodium concentration on a larger scale in clinical laboratories became possible since the emergence of the flame emission spectrometer (FES). In this technique, the sample solution is diluted and a fine mist of the diluted aliquot is blown on a flame [10]. The intensity of the light emitted is directly proportional to the concentration of sodium in the sample [10]. But in current clinical practice, most of the laboratories use indirect potentiometry using an ion-selective electrode that has a sodium selective membrane, which measures the potential generated across a sodium selective membrane, when immersed in a serum sample $[5,11]$. The potential generated is a function of the activity of sodium ions in the sample $[5,7,11]$. The activity of an element is described as a measure of the number of atoms that act completely as ions per unit volume of electrolyte solution [12]. The activity and concentration of an element in a solution may be approximated when an electrolyte solution is at higher dilution [12]. Therefore, the plasma sample is diluted before it is being measured and corrected later for the degree of dilution based on the assumption that serum contains $7 \%$ solids by volume [1]. This indirect method has been proven to be appropriate under normal physiological conditions. However, in conditions like hyperlipidemia and hyperproteinemia, the fraction of solid-phase particles is increased substantially. When the same amount of diluent is added and with subsequent calculation of the sodium level based on the normal fraction of solid-phase particles results in an erroneously low plasma sodium level [1].

Our patient initially presented with features of acute pancreatitis with underlying hypertriglyceridemia. Initially, the patient was found to be having hyponatremia. As his labs showed severe hyponatremia, he was started on hypertonic saline for one day. Later the patient's condition deteriorated and then it was determined that serum sodium results were a measurement artifact since the patient had extremely high levels of triglycerides. After realizing that it is a measurement artifact, the saline infusion was stopped and he was started on desmopressin. However, the patient deteriorated neurologically on the next day with abnormal findings on the CT scan. His overall clinical condition worsened which later resulted in death.

This extreme case demonstrates how normal sodium levels can masquerade as hyponatremia in a patient with hypertriglyceridemia which ultimately resulted in mismanagement, leading to a fatal outcome. Although the indirect ion-selective electrode method (ISE) for sodium measurement in serum has been widely used for its accuracy and validity under normal physiological conditions, the direct ISE method may be used in conditions with excessive levels of solid-phase components as this method gives a closer approximation to the actual sodium levels in such conditions. Unlike indirect ISE and flame photometry, 
direct ISE does not require prior dilution before measurement. In addition to using other methods, the water content of the plasma in patients with hyperlipidemia or hyperproteinaemia can be measured by the following formula [5]:

Plasma water content $($ percent $)=99.1-(0.1 \times \mathrm{L})-(0.07 \times \mathrm{P})$

where $\mathrm{L}$ and P refer to the total lipid and protein concentrations in $\mathrm{g} / \mathrm{L}$, respectively. With this formula, the sodium concentration can be adjusted to the normal value for plasma water content.

\section{Conclusions}

Pseudohyponatremia is a measurement artifact when the fraction of solid-phase particles is more than the physiological range. In conditions like hyperlipidemia and hyperproteinemia, excessive lipids in serum dilute the water component of serum. Since sodium is dissolved only in the aqueous phase of serum, the sodium content per unit volume of plasma is reduced. Most of the laboratories use indirect ISE, where the plasma sample is diluted prior to the measurement. Since the total sodium content in the plasma is significantly reduced, the reported lab value is an underestimate. As the patient in fact has normal sodium levels, administration of hypertonic saline may lead to serious consequences, including death as in this patient. Clinicians must be cognizant about the methods involved in the measurement to prevent mismanagement in such conditions. Direct ISE may be an alternate option in these conditions.

\section{Additional Information}

\section{Disclosures}

Human subjects: Consent was obtained or waived by all participants in this study. Conflicts of interest: In compliance with the ICMJE uniform disclosure form, all authors declare the following: Payment/services info: All authors have declared that no financial support was received from any organization for the submitted work. Financial relationships: All authors have declared that they have no financial relationships at present or within the previous three years with any organizations that might have an interest in the submitted work. Other relationships: All authors have declared that there are no other relationships or activities that could appear to have influenced the submitted work.

\section{References}

1. Turchin A, Seifter JL, Seely EW: Clinical problem-solving. Mind the gap. N Engl J Med. 2003, 349:1465-9. 10.1056/NEJMcps031078

2. Croal BL, Blake AM, Johnston J, Glen AC, O’Reilly DSJ: Absence of relation between hyponatraemia and hypothyroidism. Lancet. 1997, 350:1402. 10.1016/S0140-6736(05)65181-1

3. Moritz ML, Ayus JC: The pathophysiology and treatment of hyponatraemic encephalopathy: an update . Nephrol Dial Transplant. 2003, 18:2486-91. 10.1093/ndt/gfg394

4. Kim GH: Pseudohyponatremia: does it matter in current clinical practice? . Electrolyte Blood Press. 2006, 4:77-82. 10.5049/EBP.2006.4.2.77

5. Weisberg LS: Pseudohyponatremia: a reappraisal. Am J Med. 1989, 86:315-8. 10.1016/0002-9343(89)90302-1

6. Dhatt G, Talor Z, Kazory A: Direct ion-selective electrode method is useful in diagnosis of pseudohyponatremia. J Emerg Med. 2012, 43:348-9. 10.1016/j.jemermed.2011.07.021

7. Fortgens P, Pillay TS: Pseudohyponatremia revisited: a modern-day pitfall . Arch Pathol Lab Med. 2011, 135:516-9. 10.5858/2010-0018-RS.1

8. Frier BM, Steer CR, Baird JD, Bloomfield S: Misleading plasma electrolytes in diabetic children with severe hyperlipidaemia. Arch Dis Child. 1980, 55:771-5. 10.1136/adc.55.10.771

9. Faye S, Payne RB: Rapid measurement of serum water to assess pseudohyponatremia . Clin Chem. 1986, 32:983-6. 10.1093/clinchem/32.6.983

10. Hald PM: The flame photometer for the measurement of sodium and potassium in biological materials . J Biol Chem. 1947, 167:499-510.

11. Oesch U, Ammann D, Simon W: Ion-selective membrane electrodes for clinical use . Clin Chem. 1986, 32:1448-59. 10.1093/clinchem/32.8.1448

12. Worth HG: Plasma sodium concentration: bearer of false prophecies? . Br Med J (Clin Res Ed). 1983, 287:5678. $10.1136 /$ bmj.287.6392.567 